\title{
Doctors must meet change with courage, compassion: incoming CMA president
}

\author{
n Cite as: CMAJ 2019 September 3;191:E972. doi: 10.1503/cmaj.1095811
}

Posted on cmajnews.com on August 11, 2019.

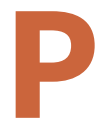

hysicians will need courage and compassion to tackle the challenges facing the profession, Canadian Medical Association (CMA) incoming president Dr. Sandy Buchman told members at the association's annual meeting in Toronto. "Consider innovation in medicine, big data, Al, virtual care, climate change, inequities in access to care, limited resources," he said. "It's not easy to adapt to changes and confront challenges like these."

CMA has been in flux, too. With the sale of MD Financial Management last year, the association restructured its enterprise and streamlined its general council meeting, introducing a year-round consultation process and annual health summit. Last year also saw changes in CMA's relationship with its provincial-territorial counterparts, including the collection of membership fees in Manitoba and Ontario and conjoint membership in Alberta and British Columbia.

"The CMA is at a turning point, and we need to work closely with all of you, our members, to create a future where our profession is as vibrant, and our patients are as healthy as possible," Buchman said.

Heading into the fall federal election, physicians have a unique opportunity to set the agenda for change, he noted. That includes advocating for a national approach to health human resource planning, a plan to mitigate the risks of climate change, and actions to address the inequities faced by marginalized Canadians.

Buchman also called for system change to improve physician health and wellbeing. "It's time to put more resources and supports in place and to address the cultures in which we work and study," he said.

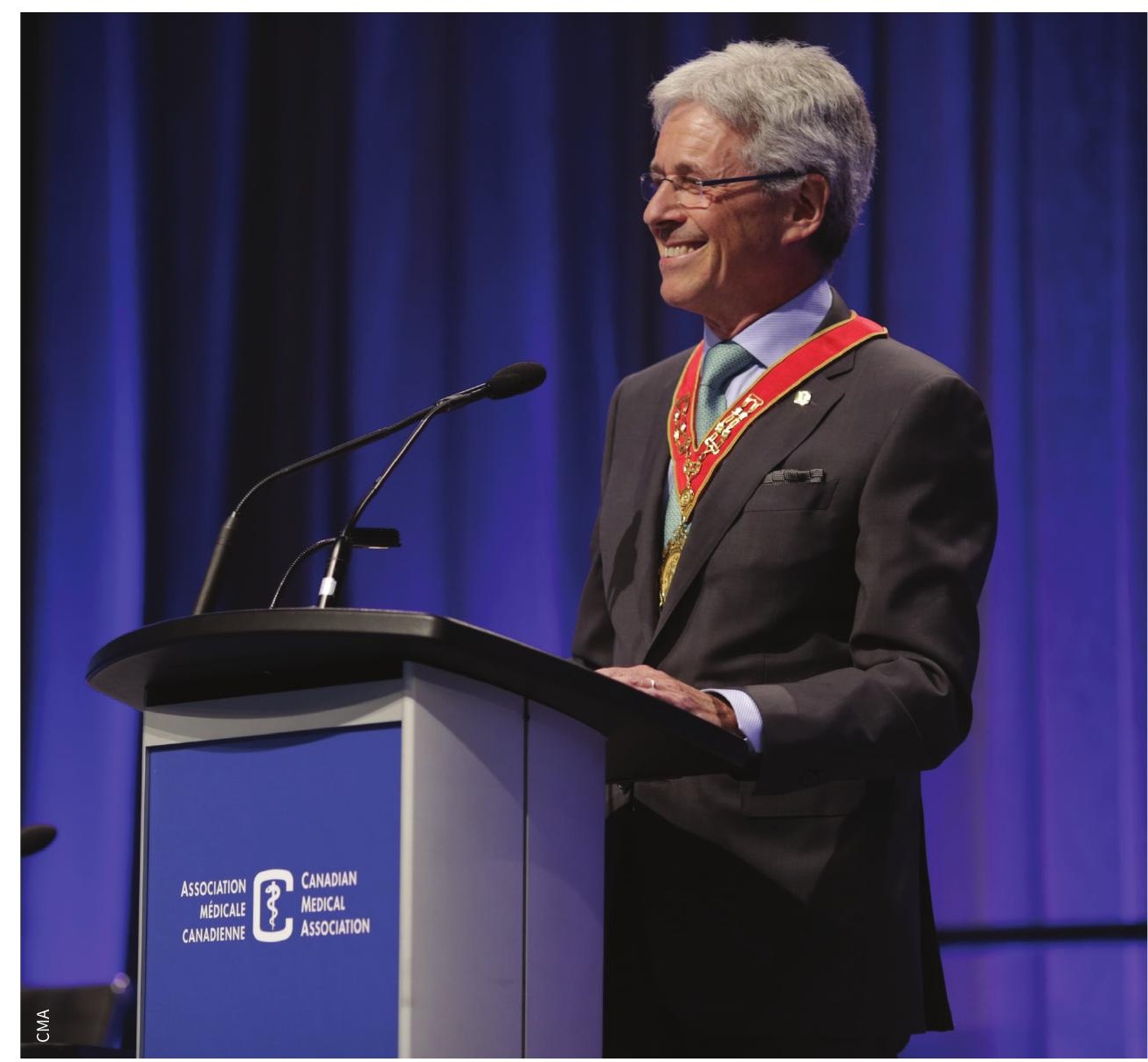

Incoming Canadian Medical Association president Dr. Sandy Buchman called for "compassionate leadership" as CMA continues its transition to a broader social enterprise.

"Compassionate leadership" will be key to these changes, Buchman argued. "In just the same way that organizations can foster a culture of bullying and fear, which leads to dysfunctional team dynamics and in the medical environment, actually poorer quality of care, so can a leader who is compassionate, kind and respectful, create a culture of psychological safety that leads to creativity and innovation in addressing the challenges of the medical workplace."
Buchman urged his colleagues to show the same compassion to themselves that they show to patients. "We work hard to ensure our patients feel listened to, supported and cared for. Do we show the same concern for our own well-being? Our colleagues? To me, it's so important to acknowledge that as humans caring for humans, we also suffer."

Lauren Vogel, CMAJ 